\title{
Citral alleviates an accelerated and severe lupus nephritis model by inhibiting the activation signal of NLRP3 inflammasome and enhancing Nrf2 activation
}

\author{
Shuk-Man Ka' ${ }^{1}$ Jung-Chen Lin², Tsai-Jung Lin ${ }^{3}$, Feng-Cheng Liư ${ }^{4}$, Louis Kuoping Chao ${ }^{5}$, Chen-Lung Ho ${ }^{6}$, \\ Li-Tzu Yeh ${ }^{7}$, Huey-Kang Sytwu ${ }^{7}$, Kuo-Feng Hua ${ }^{2,8^{*}}$ and Ann Chen ${ }^{2 *}$
}

\begin{abstract}
Introduction: Lupus nephritis (LN) is a major complication of systemic lupus erythematosus. NLRP3 inflammasome activation, reactive oxygen species (ROS) and mononuclear leukocyte infiltration in the kidney have been shown to provoke the acceleration and deterioration of $L N$, such as accelerated and severe LN (ASLN). Development of a novel therapeutic remedy based on these molecular events to prevent the progression of the disease is clinically warranted.

Methods: Citral (3,7-dimethyl-2,6-octadienal), a major active compound in a Chinese herbal medicine Litsea cubeba, was used to test its renoprotective effects in a lipopolysaccharide (LPS)-induced mouse ASLN model by examining NLRP3 inflammasome activation, ROS and COX-2 production as well as Nrf2 activation. The analysis of mechanisms of action of Citral also involved its effects on IL-1 $\beta$ secretion and signaling pathways of NLRP3 inflammasome in LPS-primed peritoneal macrophages or J774A macrophages.
\end{abstract}

Results: Attenuated proteinuria, renal function impairment, and renal histopathology, the latter including intrinsic cell proliferation, cellular crescents, neutrophil influx, fibrinoid necrosis in the glomerulus, and peri-glomerular infiltration of mononuclear leukocytes as well as glomerulonephritis activity score were observed in Citral-treated ASLN mice. In addition, Citral inhibited NLRP3 inflammasome activation and levels of ROS, NAD(P)H oxidase subunit p4 $7^{\text {phox }}$, or COX-2, and it enhanced the activation of nuclear factor E2-related factor 2 (Nrf2). In LPS-primed macrophages, Citral reduced ATP-induced IL-1 $\beta$ secretion and caspase-1 activation, but did not affect LPS-induced NLRP3 protein expression.

Conclusion: Our data show that Citral alleviates the mouse ASLN model by inhibition of the activation signal, but not the priming signal, of NLRP3 inflammasome and enhanced activation of Nrf2 antioxidant signaling.

\section{Introduction}

Lupus nephritis (LN), a disease characterized by immune complex-mediated renal inflammation and fibrosis, is classified into six classes according to the severity of renal histopathology [1], as transformation from a lower grade to a higher grade occurs $[2,3]$. Acute induction of cellular autoimmunity [4-6] and/or humoral autoimmunity [6, 7] has been implicated in the development of the resultant

\footnotetext{
*Correspondence: kuofenghua@gmail.com; annchen31717@gmail.com ${ }^{2}$ Department of Pathology, Tri-Service General Hospital, National Defense Medical Center, No. 325, Sec. 2, Cheng-Gung Road, Taipei, Taiwan, ROC Full list of author information is available at the end of the article
}

severe renal conditions, although the exact pathogenic mechanisms remain to be determined. Importantly, expression of proinflammatory cytokines, including interleukin (IL)-1 $\beta[8-10]$ and IL-18 $[9,11]$, is upregulated in animal models of accelerated and severe LN (ASLN).

The NLR family, pyrin domain containing 3 (NLRP3) inflammasome is known to control the activation of caspase-1, which cleaves pro-IL-1 $\beta$ and pro-IL-18 to form mature IL-1 $\beta$ and IL-18 $[12,13]$. A priming signal from pathogen-associated molecular patterns and an activation signal, e.g., ATP from damaged cells, are both required for full activation of the NLRP3 inflammasome 
[12-14]. Immune complexes can trigger the activation of the NLRP3 inflammasome in macrophages from systemic lupus erythematosus (SLE) patients and animal models, leading to cell and tissue damage $[9,15,16]$. We [9] and others $[10,16]$ have shown that increased production of IL-1 $\beta$ resulting from NLRP3 inflammasome activation and $\mathrm{T}$ cell activation occurs in mouse models of $\mathrm{LN}$, suggesting the NLRP3 inflammasome and its downstream pathway as an important mechanism underlying the evolution of LN.

In addition, oxidative stress can potentiate inflammatory processes by activating NF-kB, thereby stimulating production of pro-inflammatory cytokines [17-19] and has been implicated in the progression/deterioration of LN in patients, leading to the development of severe renal conditions $[17,18,20]$. The nuclear factor E2-related factor 2 (Nrf2) antioxidant signaling pathway confers protection against oxidative stress and prevents cell and tissue injury $[17,21,22]$, and deletion of the Nrf2 gene results in a lupus-like autoimmune nephritis in mice [22, 23]. Disruption of the Nrf2 gene has been shown to result in increased production of IL-1 $\beta$, TNF- $\alpha$, and IL- 6 in mice [24-26]. Recently, we showed that expression of Nrf2 and its downstream molecules, heme oxygenase- 1 and glutathione peroxidase, is reduced in mouse models of diabetic nephropathy, IgA nephropathy, and ASLN, and that these changes can be prevented by treatment with Chinese herbal medicine-derived pure components with Nrf2mediated anti-oxidant activity [14, 27, 28]. In addition, reactive oxygen species (ROS) can cause NLRP3 inflammasome activation [14, 29], and both oxidative stress and inflammation have been shown to be involved in the development of $\operatorname{LN}[18,30]$ and its progression and deterioration $[17,27]$.

Citral (3,7-dimethyl-2,6-octadienal), a major active compound found in Litsea cubeba, a traditional Chinese herbal medicine, can inhibit activation of macrophages and $\mathrm{NF}-\mathrm{kB}$ and the production of pro-inflammatory cytokines, including IL-1 $\beta$ [31] and also shows potent antioxidant activity $[32,33]$. In a recent study, we demonstrated that the renoprotective effect of Citral results from activation of the Nrf2 antioxidant pathway and inhibition of NF$\mathrm{KB}$ activation in the early stage of adriamycin-induced focal segmental glomerulosclerosis in mice [34] (patented by Taiwan, I463979 and USA, 8,993,637). However, whether Citral has an effect on the accelerated and progressive stage of immune complex-mediated glomerular disorders, such as ASLN, remains to be determined. In this study, we tested the hypothesis that Citral can attenuate an ASLN model in mice and examined the modes of action of its renoprotective effect. We clearly show that by inhibiting the activation signal of NLRP3 inflammasome and increasing Nrf2 anti-oxidative activity, Citral effectively prevented the development of ASLN.

\section{Methods}

Preparation of Citral (3, 7-dimethyl-2-7-octadienal)

Citral was isolated from fruits of $L$. cubeba, a traditional Chinese herbal medicine as described previously (purity $\geq 96 \%$ ) [34].

\section{Mouse ASLN model and experimental protocol}

A mouse ASLN model was used in which female NZB/ Wf1 mice (8 weeks old) were injected intraperitoneally with either saline or $0.8 \mu \mathrm{g} / \mathrm{g}$ body weight of lipopolysaccharide (LPS) (Sigma-Aldrich, St. Louis, MO, USA) in saline twice weekly for 5 weeks as described previously [27]. Starting 2 days before LPS/saline injection, Citral (200 mg/kg of body weight) or vehicle (corn oil) was administered daily by gavage throughout the study. The mice were sacrificed at the end of week 5 after the start of disease induction. All animal experiments were performed with the approval of the Institutional Animal Care and Use Committee of The National Defense Medical Center, Taiwan, and were conducted in accordance with national guidelines.

\section{Clinical and pathological evaluation}

Urine samples were collected in metabolic cages for $6 \mathrm{~h}$ at the end of each week, and urinary albumin and creatinine $(\mathrm{Cr})$ were measured as described previously [35]. Serum samples were collected at the end of each week to measure levels of blood urea nitrogen (BUN) and $\mathrm{Cr}$ as described previously [35]. At the end of the study, renal pathology and scoring of glomerular proliferation, fibrinoid necrosis, neutrophil infiltration, crescent formation, and peri-glomerular inflammation was performed on 50 randomly sampled glomeruli [9], and a glomerulonephritis activity score (range 0-24) was calculated as described previously [36].

Immunofluorescence, immunohistochemistry, and terminal deoxynucleotidyl transferase dUTP nick end labeling (TUNEL)

Frozen sections of renal tissues were stained with fluorescein isothiocyanate (FITC)-conjugated antibodies against IgG or C3 (Cappel Lab. Inc., Cochranville, PA, USA) as described previously [37] and semiquantitative analysis of the total immunofluorescence intensity performed as described previously [38]. Formalin-fixed and paraffin-embedded renal sections were incubated with antibodies against CD3 (pan-T cell), or F4/80 (monocytes/macrophages) (both from Serotec, Kidlington, UK), followed by biotinylated second antibodies, and avidin-biotin-peroxidase complex (both from Dako Denmark A/S, Glostrup, Denmark) as described previously [28].

The TUNEL assay was used to detect apoptosis in renal sections using an ApopTag Plus Peroxidase in Situ Apoptosis Detection kit (Chemicon International, Inc., 
Billerica, MA, USA) according to the manufacturer's instructions. Numbers of CD3-, F4/80-, or TUNELpositive cells were determined using PAX-it software as described previously [28].

\section{Serum levels of autoantibody}

Serum anti-dsDNA antibodies were measured using an anti-dsDNA ELISA kit (Alpha Diagnostic, TX, USA) according to the manufacturer's instructions. The absorbance at $450 \mathrm{~nm}$ was measured using an ELISA plate reader (Bio-Tek, Winooski, VT, USA).

\section{Flow cytometry}

Isolated splenocytes were double-stained with FITCconjugated antibodies against mouse CD3 (pan-T cells), CD4, CD8 (T cell subsets), or CD19 (B cell marker) and phycoerythrin (PE)-conjugated anti-mouse CD69 antibodies (H1.2 F3; marker of activated $\mathrm{T}$ and $\mathrm{B}$ cells) (BD Biosciences, San Diego, CA, USA) and analyzed on a FACSCalibur (BD Biosciences) as described previously [37].

For intracellular staining of IFN- $\gamma$ or IL-4, splenocytes were cultured for $5 \mathrm{~h}$ in 24-well microtiter plates in the presence or absence of phorbol myristate acetate, ionomycin, and monensin (all from Sigma-Aldrich). They were then stained for 30 minutes on ice with FITC-conjugated anti-mouse CD3 antibodies (BD Biosciences), fixed in $1 \%$ paraformaldehyde (Sigma-Aldrich), and re-suspended in permeabilization buffer, as described previously [37], then intracellular cytokines was stained for 30 minutes on ice with PE-conjugated antibodies against IFN- $\gamma$ or IL-4 (BD Biosciences), followed by flow cytometric analysis using a FACSCalibur (BD Biosciences).

\section{Renal levels of ROS}

Renal ROS levels were estimated using a chemoluminescence assay for superoxide anion, the results being presented as reactive luminescence units (RLU) per $15 \mathrm{mi}$ nutes per milligram dry weight (i.e., RLU/15 min/mg dry weight) as described previously [9].

\section{Renal activities of NF-KB and cytoplasmic caspase-1 activity} and serum levels of IL-1 $\beta$ and prostaglandin E2 (PGE2)

Renal cytoplasmic and nuclear proteins were extracted using a nuclear extract kit (Active Motif, Carlsbad, CA, USA) according to the manufacturer's instructions. Nuclear NF-kB p65 activation was quantified using an ELISA-based TransAM NF-кB kit (Active Motif) according to the manufacturer's protocol. Caspase-1 activity in the cytoplasmic fraction was measured using caspase-1 activity kits (R\&D Systems, Minneapolis, MN, USA) according to the manufacturer's instructions, and is presented as a value relative to the protein concentration. Serum levels of IL-1 $\beta$ or PGE2 were measured using commercial ELISA kits (both from R\&D Systems), according to the manufacturer's instructions.

\section{Western blots to estimate levels of nuclear Nrf2 and cytosolic NAD(P)H oxidase subunit $\mathrm{p} 47^{\text {phox }}$,} cyclooxygenase-2 (COX-2), NLRP3, and IL-1 $\beta$ in the kidney Cytoplasmic and nuclear proteins extracted from renal tissues as described above were used for Western blot analysis using antibodies against Nrf2, p47 ${ }^{\text {phox }}$, COX-2, or IL-1 $\beta$ (all from Santa Cruz Biotechnology, Santa Cruz, CA, USA) or NLRP3 (Enzo Life Sciences Inc, Farmingdale, NY, USA). Antibodies against Lamin A (nuclear proteins) or $\beta$-actin (cytosolic proteins), both from Santa Cruz, were used as internal controls.

\section{In vitro studies}

Effect of Citral on LPS/ATP-induced IL-1 $\beta$ secretion by primary peritoneal macrophages

Peritoneal macrophages, elicited by an intraperitoneal (IP) injection in 8-week-old female NZB/Wf1 mice with $4 \%$ sterile thioglycollate medium as described previously [14], were harvested and grown in RPMI 1640 medium supplemented with $2 \mathrm{mM}$ L-glutamine, $100 \mathrm{U} / \mathrm{ml}$ of penicillin, $100 \mu \mathrm{g} / \mathrm{ml}$ of streptomycin, $2.5 \mu \mathrm{g} / \mathrm{ml}$ of amphotericin $\mathrm{B}$, and $10 \%$ heat-inactivated fetal calf serum (all from Gibco, Grand Island, NY, USA) at $37{ }^{\circ} \mathrm{C}$ in a $5 \% \mathrm{CO}_{2}$ incubator. The cells $\left(2.5 \times 10^{6}\right.$ in $500 \mu \mathrm{l}$ of medium) were incubated for 30 minutes with Citral or saline, then LPS (Sigma-Aldrich; final concentration $1 \mu \mathrm{g} / \mathrm{ml}$ ) was added for $5.5 \mathrm{~h}$. The cells were then incubated for 30 minutes with addition of ATP (Sigma-Aldrich; $5 \mathrm{mM}$ ) for $30 \mathrm{mi}$ nutes, then IL-1 $\beta$ levels in the culture medium were measured using an ELISA kit (R\&D Systems), according to the manufacturer's instructions.

\section{Effect of Citral on NLRP3 inflammasome activation in a macrophage cell line}

The murine macrophage cell line J774A.1 was purchased from the American Type Culture Collection (Rockville, MD, USA). The cells $\left(2 \times 10^{6}\right.$ in $2 \mathrm{ml}$ of medium) were (1) incubated for 30 minutes with or without Citral, then LPS (final concentration $1 \mu \mathrm{g} / \mathrm{ml}$ ) or saline was added for $5.5 \mathrm{~h}$, and incubated for 30 minutes with $5 \mathrm{mM}$ ATP or saline, or (2) incubated for $5.5 \mathrm{~h}$ with LPS $(1 \mu \mathrm{g} / \mathrm{ml})$ or saline and the cells were washed with saline, then Citral or saline was added for 30 minutes, followed by addition of $5 \mathrm{mM}$ ATP or saline for 30 minutes. In both assays, IL-1 $\beta$ levels in the culture medium were then measured using an ELISA kit (R\&D Systems), while levels of NLRP3, activated caspase-1 (p10), or pro-caspase-1 (p45) in the cells were measured by western blotting, as described previously [28]. 


\section{Data analysis}

For animal experiments, the results are presented as the mean \pm standard error of the mean (SEM) and comparisons between two groups were performed using Student's $t$ test except in the case of differences in urinary albumin/ $\mathrm{Cr}$ ratios, which were examined using one-way analysis of variance (ANOVA). For experiments using cultured macrophages, all values are given as the mean $\pm S D$, and data

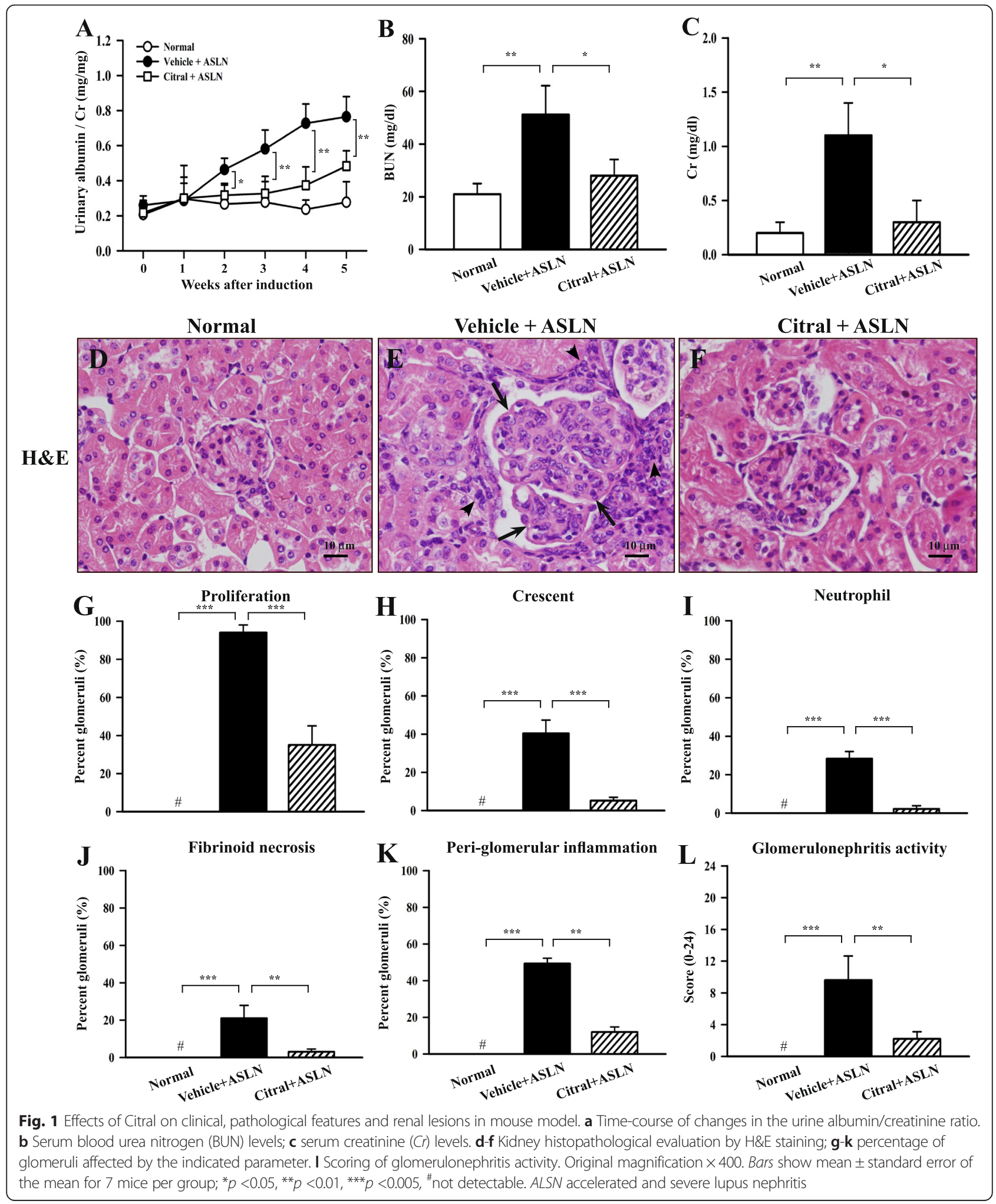


analysis was performed using one-way ANOVA with subsequent Scheffé test. A $p$ value $<0.05$ was considered statistically significant.

\section{Results}

Citral improves albuminuria and renal function

A progressive type of mouse ASLN model was used in which female NZB/Wf1 mice (8 weeks old) were injected IP with LPS twice weekly for 5 weeks, and starting 2 days before LPS injection were given Citral or vehicle daily by gavage until the end of the study. As shown in Fig. 1a, vehicle + ASLN mice developed albuminuria which began at the end of week 2 and increased up to the end of the study. However, in Citral-treated ASLN (Citral + ASLN) mice, this effect was markedly inhibited. Similarly, improved renal function was seen at the end of week 5 in Citral + ASLN mice compared to vehicle + ASLN mice as demonstrated by serum levels of BUN (Fig. 1b) and $\mathrm{Cr}$ (Fig. 1c) (both $p<0.05$ ).

\section{Citral prevents severe renal injury and moderates systemic $T$ cell activation}

Light microscopy showed that compared to normal control mice (Fig. 1d), vehicle + ASLN mice had severe renal pathological lesions, including intrinsic cell proliferation (Fig. 1e, g), cellular crescents (Fig. 1e, h), neutrophil influx (Fig. 1e, i), fibrinoid necrosis (Fig. 1e, j) in the glomerulus, and peri-glomerular infiltration of mononuclear leukocytes (Fig. 1e, k). Again, the severity of these renal lesions was markedly reduced in Citral + ASLN mice (all $p<0.01$ ) (Fig. 1f, g-k), although they still had very mild renal pathological changes. We also calculated a histopathology score, the glomerulonephritis activity score [36], developed to determine glomerulonephritis activity for the assessment of $\mathrm{LN}$ in humans, and found that this was markedly increased in vehicle + ASLN mice compared to normal controls and significantly lower in Citral + ASLN mice (Fig. 11). In addition, as shown in Fig. 2, apoptosis was frequently seen in the kidneys of vehicle + ASLN mice and was significantly decreased in the glomeruli and renal tubules of Citral + ASLN mice, in which there were only a few apoptotic figures.

Immunofluorescence studies demonstrated marked deposits of IgG and C3 in the glomeruli of vehicle + ASLN mice compared to normal control mice (total intensity score $204 \pm 18$ vs. $31 \pm 8, p<0.005$ ), which were still present in the glomeruli of the Citral + ASLN mice (total intensity score $211 \pm 23$ ). Although significantly increased serum levels of anti-dsDNA antibody were seen in vehicle + ASLN (1.6 \pm 0.2 optical density (OD) vs. $0.6 \pm 0.1 \mathrm{OD}, p<0.01)$ and Citral + ASLN $(1.4 \pm 0.3$ $\mathrm{OD}$ vs. $0.6 \pm 0.1 \mathrm{OD}, p<0.01)$ mice compared to normal control mice, there was no significant difference in serum levels of the autoantibody between vehicle + ASLN and

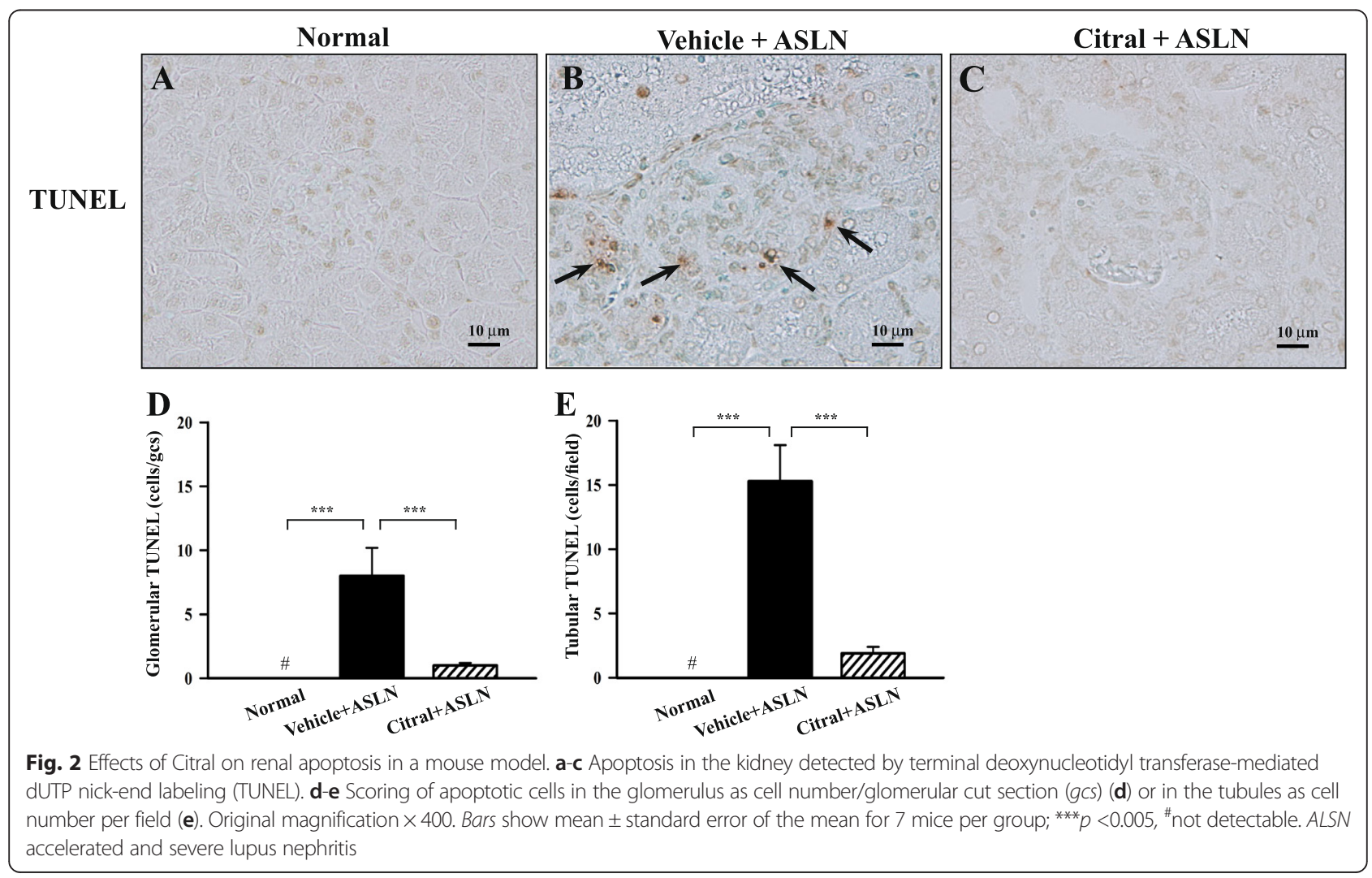


Citral + ASLN mice. The results obtained from both experiments suggest that Citral did not have inhibitory effects on humoral immune response in the mice at the dose used throughout the study.

Flow cytometric analysis of spleen cells showed that activation of $\mathrm{CD}^{+} \mathrm{T}$ cells (Fig. 3a), $\mathrm{CD}^{+} \mathrm{T}$ cells (Fig. $3 \mathrm{~b}$ ), and $\mathrm{CD}^{+} \mathrm{T}$ cells (Fig. 3c), as shown by the percentage of such cells expressing the activation marker CD69, was significantly increased in vehicle + ASLN mice compared to normal controls, and this effect was again markedly inhibited in Citral + ASLN mice (Fig. 3a-c). In contrast, although activation (CD69 positivity) of B cells $\left(\mathrm{CD} 19^{+}\right.$cells) was significantly increased in vehicle + ASLN mice compared to normal controls, there was no significant difference between the vehicle + ASLN and Citral + ASLN mice (Fig. 3d). The percentage of total T cells $\left(\mathrm{CD}^{+}\right.$cells) expressing IFN- $\gamma$ (Fig. 3e) or IL-4 (Fig. 3f) was greatly increased in vehicle + ASLN mice compared to normal controls, and this effect was markedly inhibited in Citral + ASLN mice.

\section{Citral inhibits NLRP3 inflammasome activation}

As activation of the NLRP3 inflammasome in macrophages has been shown to be involved in the progression of spontaneous SLE in NZB/Wf1 mice [9], we performed several experiments to examine the mechanism of action of Citral in ASLN mice and in vitro cultures.

\section{Animal model}

Significant renal infiltration of $\mathrm{T}$ cells $\left(\mathrm{CD}^{+}\right)$was seen at the end of week 5 in vehicle + ASLN mice compared to normal control mice and this effect was markedly inhibited in Citral + ASLN mice (Fig. 4a-c, g, h). In addition, in vehicle + ASLN mice there was significant infiltration of macrophages $\left(\mathrm{F} 4 / 80^{+}\right)$into the kidney and this effect was also significantly decreased in Citral + ASLN mice (Fig. 4d-f, i, j). Renal nuclear NF-kB p65 activity was also significantly increased in vehicle + ASLN mice compared to normal controls and was also significantly inhibited in Citral + ASLN mice (Fig. 4k).

Western blotting showed increased NLRP3 expression in the kidneys of vehicle + ASLN mice compared to normal control mice $(p<0.01)$ and this effect was prevented by Citral treatment $(p<0.005)$ (Fig. 5a, b). Vehicle + ASLN mice also expressed significantly higher renal IL$1 \beta$ levels (Fig. 5a, c) and renal caspase- 1 activity than normal control mice (Fig. 5d) and Citral administration resulted in a significant reduction in both (both $p<0.01$ ). In addition, significantly increased serum levels of IL-1 $\beta$ were observed in vehicle + ASLN mice, compared to

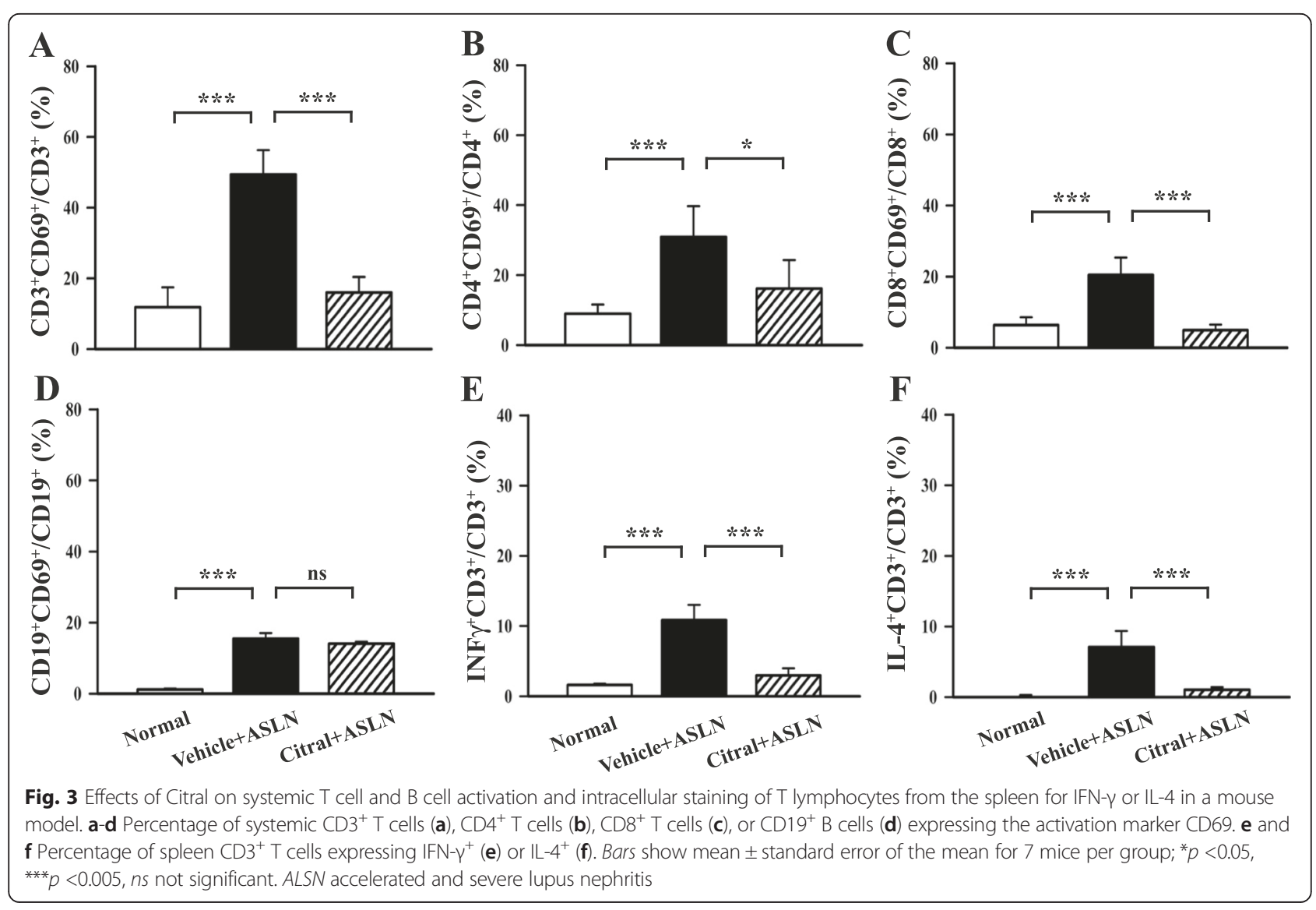




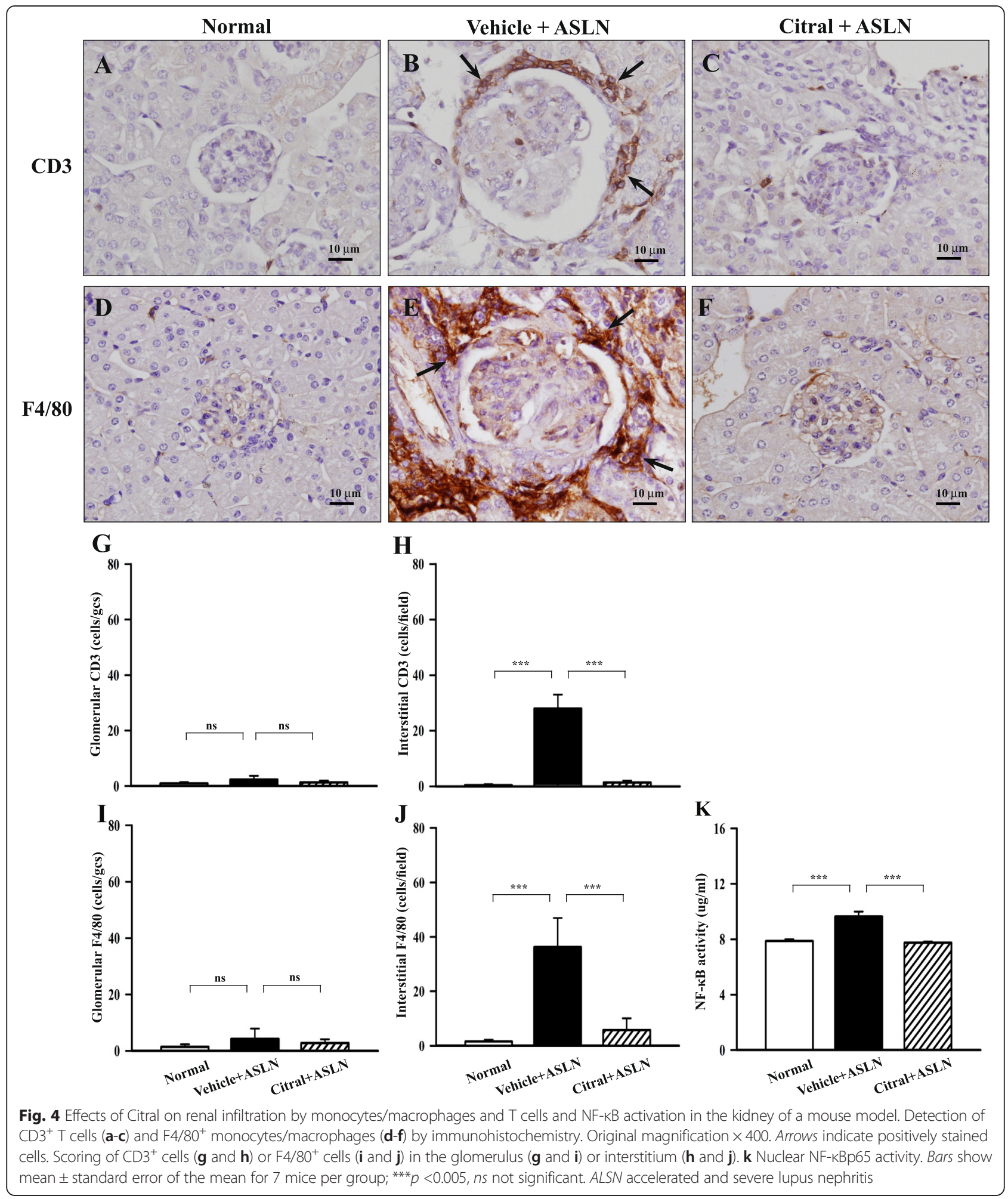

normal control mice $(86.2 \pm 15.0 \mathrm{pg} / \mathrm{ml}$ vs. $46.3 \pm$ $8.5 \mathrm{pg} / \mathrm{ml} ; p<0.05)$, and Citral administration resulted in decreased serum levels of IL-1 $\beta$, although there was no statistical significance $(86.2 \pm 15.0 \mathrm{pg} / \mathrm{ml}$ vs. $61.8 \pm$ $9.2 \mathrm{pg} / \mathrm{ml} ; p=0.06)$.
In vitro studies of the effect of Citral on LPS + ATP-induced IL-1 $\beta$ secretion by naïve peritoneal macrophage cultures or the mouse macrophage cell line

Full activation of the NLRP3 inflammasome requires both a priming signal (e.g., LPS) and an activation signal 


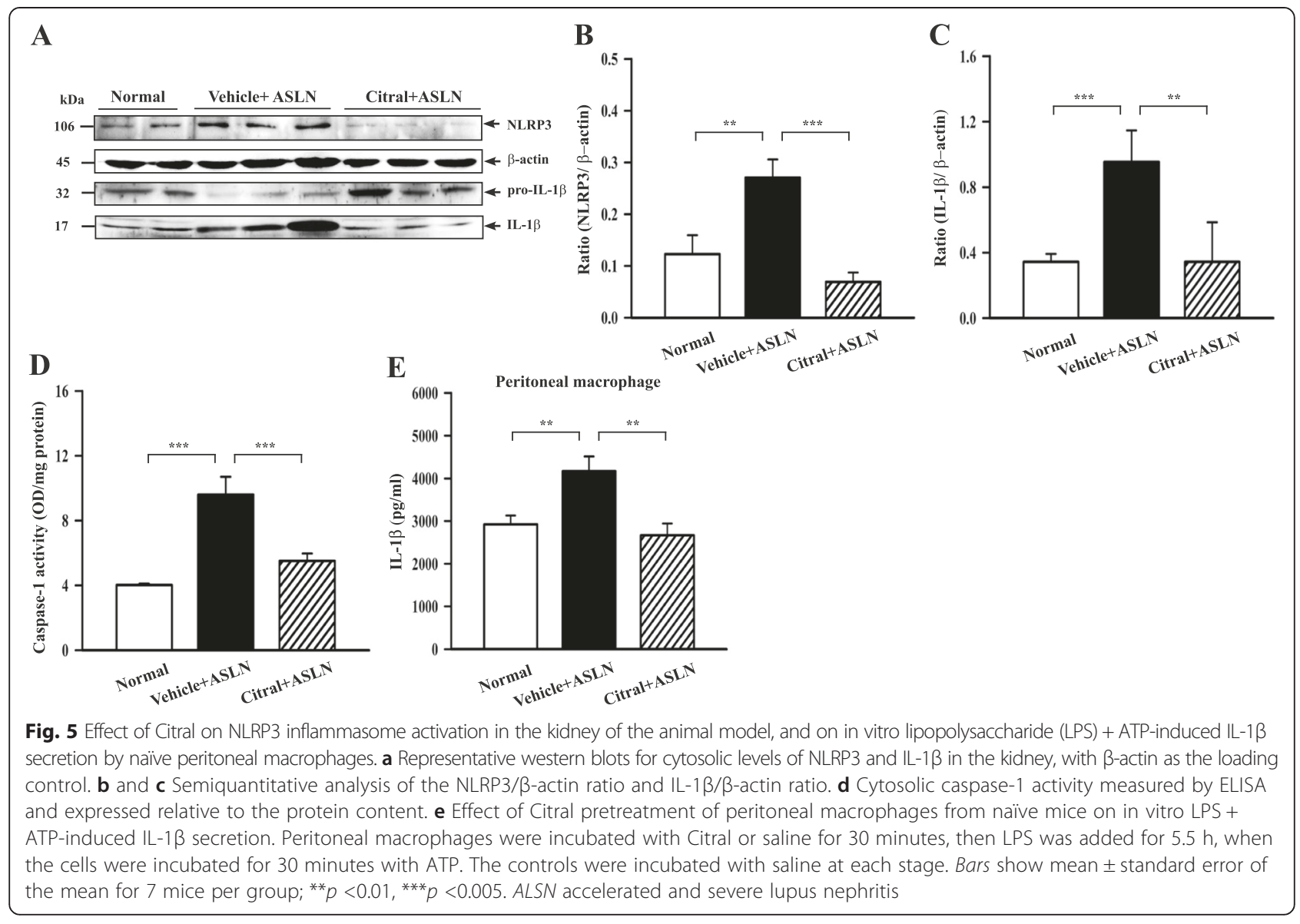

(e.g., ATP) [14, 39]. In the first study, peritoneal macrophages from untreated 8-week-old female NZB/Wf1 mice were incubated in vitro for 30 minutes with Citral or saline, followed by addition of LPS for $5.5 \mathrm{~h}$, then were incubated with ATP for 30 minutes, when IL-1 $\beta$ levels in the culture medium were measured by ELISA; controls were cells incubated at each stage with saline. The results showed that Citral completely blocked LPS + ATP-induced IL-1 $\beta$ production (Fig. 5e).

In the second study, we examined the effect of Citral on each step of LPS/ATP-induced NLRP3 inflammasome activation in the mouse macrophage cell line J774A.1. In the first experiment, control J774A.1 macrophages were left untreated, while others were incubated with or without different concentrations of Citral for 30 minutes before addition of LPS for $5.5 \mathrm{~h}$, and incubation with ATP for 30 minutes, then IL- $1 \beta$ secretion was measured by ELISA and caspase- 1 generation by western blotting. The results showed that Citral significantly inhibited IL-1 $\beta$ secretion in a dose-dependent manner (Fig. 6a), but did not affect the generation of active caspase-1 (Fig. 6b). In the second experiment, we incubated the cells with LPS for $5.5 \mathrm{~h}$, washed with saline, before addition of vehicle or different concentrations of
Citral for 30 minutes, followed by ATP stimulation for 30 minutes, and found that Citral inhibited both IL-1 $\beta$ secretion (Fig. 6c) and caspase- 1 activation (Fig. 6d) in a dose-dependent manner. These results demonstrate that Citral inhibits the production and secretion of IL-1 $\beta$ through activation of the NLRP3 inflammasome. We also tested its ability to inhibit expression of both NLRP3 and pro-IL-1 $\beta$ (IL-1 $\beta$ precursor) proteins in LPS-activated J774A.1 cells by incubating the cells with different concentrations of Citral for 30 minutes before addition of LPS for another $6 \mathrm{~h}$, and found that Citral had no effect on LPS-induced NLRP3 expression (Fig. 6e, f), but inhibited LPS-induced pro-IL-1 $\beta$ expression in a dose-dependent manner (Fig. 6e, g).

Citral inhibits the increase in ROS, NAD(P)H oxidase subunit $\mathrm{p} 47^{\text {phox }}, \mathrm{COX}-2$, or PGE2 levels, and it enhances nuclear Nrf2 levels

Citral has been shown to be an antioxidant in inflammatory diseases $[14,40]$ and inhibits LPS-induced ROS production in macrophages $[34,40]$. As shown in Fig. 7a, renal levels of superoxide anion were significantly increased in vehicle + ASLN mice compared to normal controls $(p<0.01)$ and this effect was significantly inhibited in 


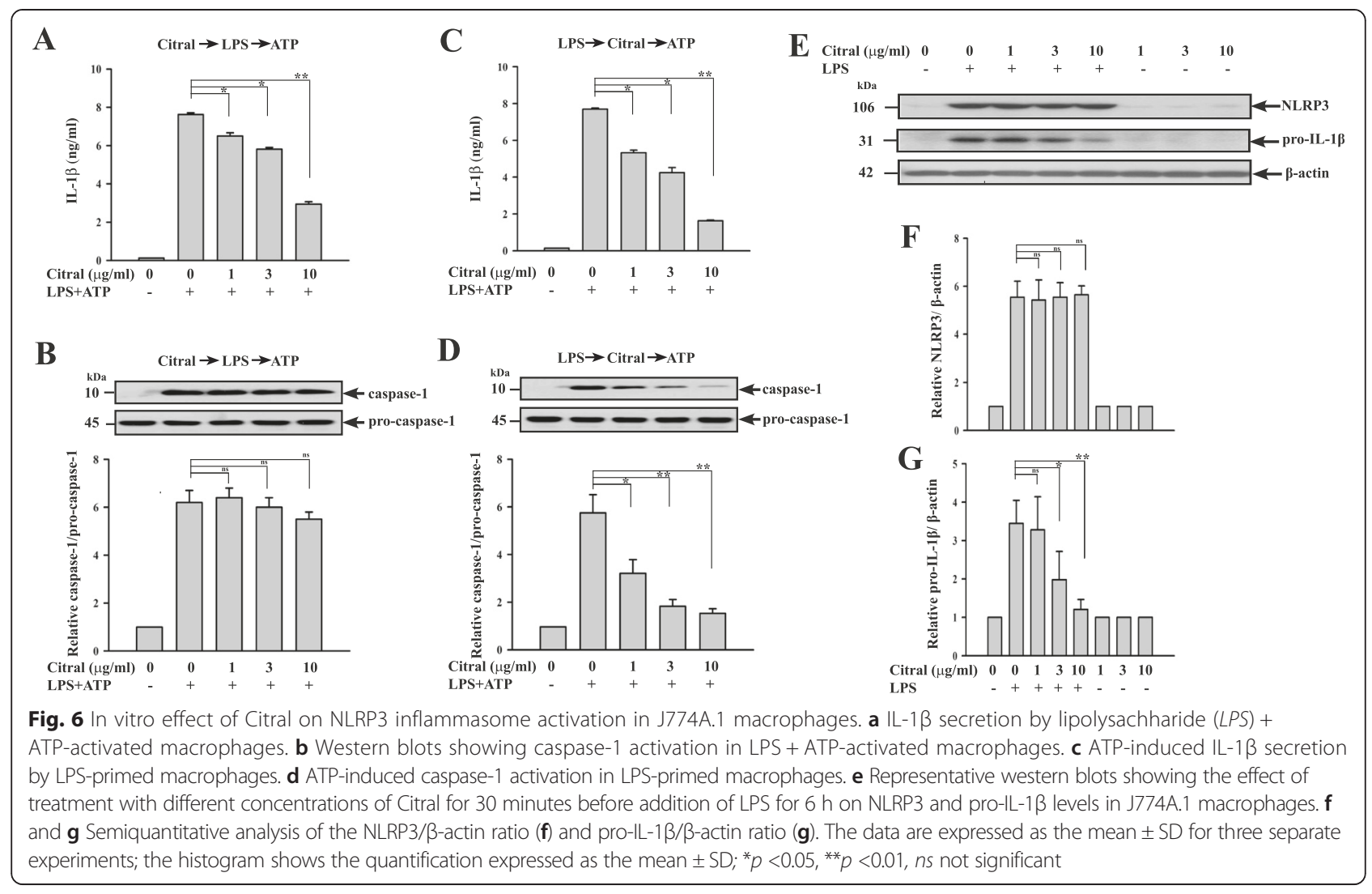

Citral + ASLN mice $(p<0.05)$. Renal cytosolic $\mathrm{p} 47^{\text {phox }}$ levels in vehicle + ASLN mice were also greatly increased compared to normal control mice $(p<0.01)$, and this effect was significantly decreased by Citral treatment $(p<0.05)$ to levels similar to those in normal control mice (Fig. 7b, c). Next, we measured renal cytosolic COX-2 levels and serum levels of PGE2, a downstream molecule of COX-2, and found that renal COX-2 levels (Fig. 7b, d) and serum PGE2 levels (Fig. 7e) were significantly increased in vehicle + ASLN mice compared to normal control mice (both $p<0.01$ ), and both effects were significantly inhibited in Citral + ASLN mice (both $p<0.05$ ). We then evaluated nuclear levels of Nrf2 in renal tissues, as this transcription factor triggers an antioxidant pathway in renal inflammation and fibrosis [27, 28]. As shown in Fig. 7f and g, vehicle + ASLN mice had significantly lower nuclear levels of Nrf2 than normal control mice $(p<0.05)$ and this effect was significantly decreased in Citral + ASLN mice $(p<0.05)$.

\section{Discussion}

In the present study, as persistent inflammatory episodes and oxidative stress are implicated in both the development and progression/deterioration of LN [20, 27], we examined whether Citral could alleviate the clinical manifestations and pathological changes in an ASLN model in NZB/Wf1 mice. Our results showed that Citral inhibited the development of ASLN, as demonstrated by reduced albuminuria, improved renal function, and improved renal histopathology in intrinsic cell proliferation, cellular crescents, neutrophil influx, fibrinoid necrosis in the glomerulus, and peri-glomerular infiltration of mononuclear leukocytes, and the glomerulonephritis activity score. Mechanistic studies showed that inhibition of the activation signal of NLRP3 inflammasome and enhanced activation of Nrf2 antioxidant signaling were involved in the major mechanisms of action for the renoprotective effects of Citral.

Bachiega et al. (2011) [31] demonstrated that Citral reduces LPS-induced IL- $1 \beta$ secretion in macrophages. We further examined the inhibitory effect of Citral on NLRP3 inflammasome activation was verified by naïve peritoneal macrophages from untreated mice incubated with Citral or saline, then tested for LPS/ATP-induced IL-1 $\beta$ secretion (Fig. 5e). Citral significantly reduced both IL-1 $\beta$ secretion (Fig. $6 \mathrm{c}$ ) and caspase-1 activation (Fig. 6d) when added to cultures of J774A.1 macrophages after LPS priming, but before ATP stimulation, suggesting that it reduces IL- $1 \beta$ secretion by inhibiting ATP-mediated caspase- 1 activation. In addition, addition of Citral before LPS priming also caused reduced IL-1 $\beta$ secretion (Fig. 6a), but did not reduce caspase-1 activation (Fig. 6b). Although Citral did not affect NLRP3 expression in LPS-activated macrophages (Fig. 6e, f), it reduced LPS- 


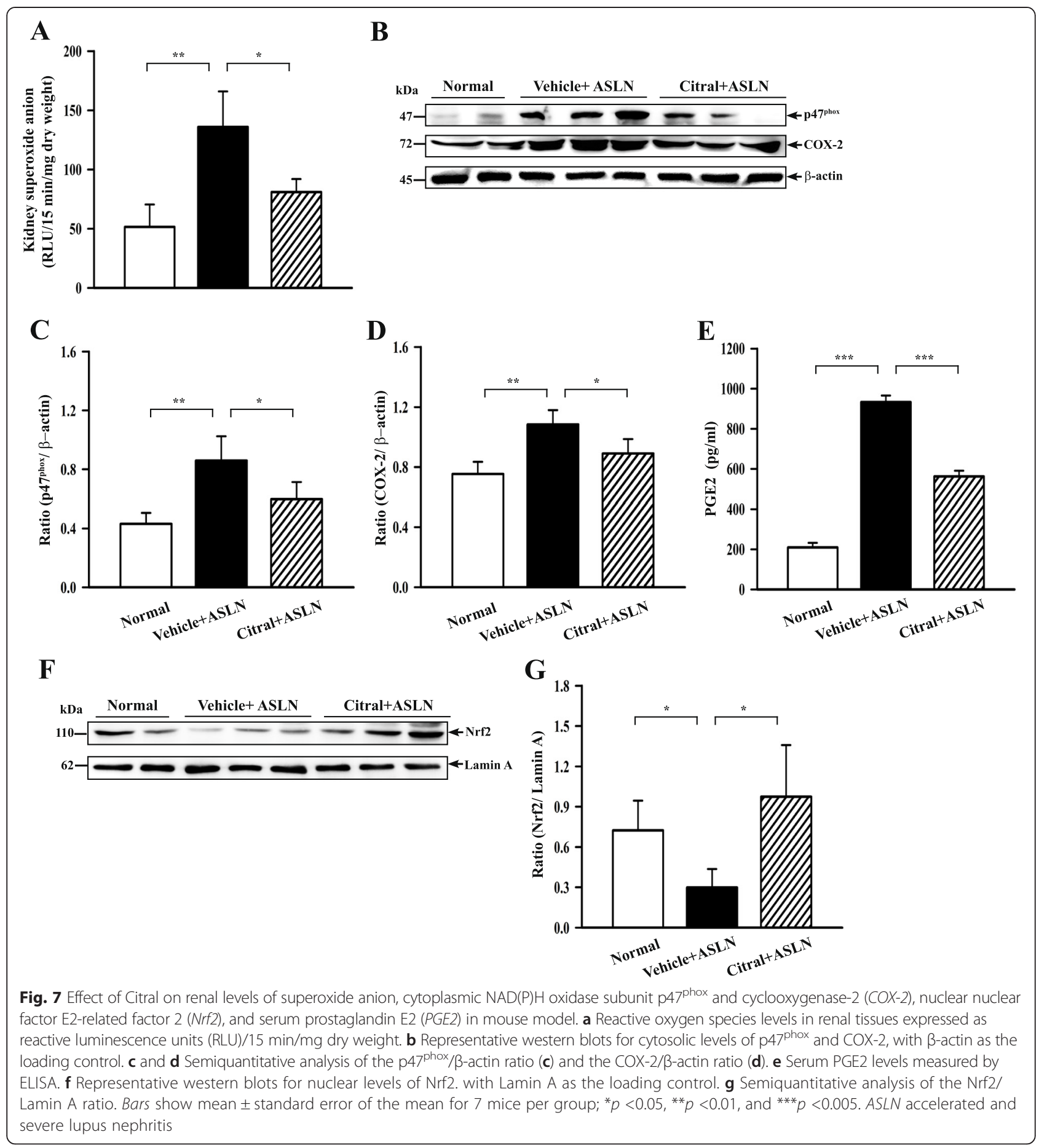

induced pro-IL-1 $\beta$ expression (Fig. 6e, g). We therefore infer that the Citral-mediated decrease in IL- $1 \beta$ secretion in LPS-primed macrophages involves downregulation of pro-IL-1 $\beta$ production. Collectively, our in vitro data indicate that Citral inhibits IL- $1 \beta$ secretion through: (1) reducing IL-1 $\beta$ precursor (pro-IL-1 $\beta$ ) protein expression (Fig. 6e) and (2) inhibiting ATP-induced caspase-1 activity (Fig. 6d). These results indicate that Citral inhibits both
LPS-mediated pro-IL-1 $\beta$ expression and ATP-mediated activation signal of NLRP3 inflammasome.

Interestingly, the fact that Citral administration in vivo resulted in reduced renal NLRP3 expression in Citraltreated mice (Citral + ASLN mice) suggests that other molecular pathways may be involved in the mechanism of action of Citral in this mouse model of ASLN. In this regard, for instance, binding of IL- $1 \beta$ to IL-1 receptors 
was found to promote production of COX-2 [41]. In our recent report, COX-2 promotes NLPR3 activation and IL-1 $\beta$ protein secretion [39]. In the present study, we demonstrated that reduced renal COX-2 levels were seen in Citral + ASLN mice compared to vehicle + ASLN mice (Fig. 7b, d). The data suggest the COX-2-mediated activation of NLRP3 inflammasome may be one of attributed pathways responsible for the renoprotective effects of Citral. It should be noted, however, that to determine whether the NLRP3 inflammasome-associated molecules and related signaling pathways are crucial in the mechanisms of Citral for its renoprotective effects, the ASLN model should be used in mice deficient in each of the several molecules or with neutralizing antibodies, and all these tests deserve further investigation. Another issue is whether the effect of Citral is specific for the NLRP3inflammasome-mediated IL- $1 \beta$ production. Other inflammasomes, such as AIM2 and NLRC4 inflammasomes, deserve further evaluation of the renoprotective effects of the compound.

Finally, Citral prevented kidney inflammation and resultant fibrosis $\mathrm{n}$ this severe $\mathrm{LN}$ model by inhibiting the systemic immune response. Abnormal systemic function of $\mathrm{T}$ and $\mathrm{B}$ cells in innate and adaptive immune responses is involved in the canonical pathophysiological pathways underlying the development and progression of $\operatorname{LN}[4,6]$. In the present study, although we failed to show any inhibitory effects of Citral on B cell activation or on immune deposits in the kidneys, Citral administration markedly inhibited $\mathrm{CD}^{+}{ }^{+} \mathrm{T}$ cell activation (Fig. 3b) and the production of IFN- $\gamma$ by these cells (Fig. 3e). Importantly, $\mathrm{T}$ helper (Th)1 cells can promote the activation of macrophages by producing IFN- $\gamma$, and macrophages are involved in NLRP3 inflammasome activation, which may provide IL-1 $\beta$ signaling to activate $\mathrm{T}$ cells $[42,43]$. The beneficial effect of Citral administration in this severe LN model may involve an effect on Th cell responses. This potential mode of action of Citral in its renoprotective effects is worth further investigation.

Blockade of ROS production in studies involving the use of chemical scavengers of ROS, pharmacological inhibitors of $\mathrm{NAD}(\mathrm{P}) \mathrm{H}$ oxidase, or siRNA-mediated knockdown of $\mathrm{p}^{2} 2^{\text {phox }} \mathrm{NAD}(\mathrm{P}) \mathrm{H}$ oxidase has been shown to inhibit NLRP3 inflammasome activation in response to a wide range of stimuli $[14,44]$. Our previous study showed that inflammasome activation is mediated by ROS by using ROS inhibitors [45] Taken together, we infer that reduced ROS generation by Citral may explain the resultant decreased pro-IL-1 $\beta$ protein levels by the compound. Furthermore, we showed that increased ROS production was seen in the kidney in ASLN mice and that Citral activated Nrf2 in ASLN mice, supporting the ideas that oxidative stress contributes to the pathogenesis of ASLN and that enhanced activation of the Nrf2 antioxidant pathway prevents the renal damage associated with severe LN. NLRP3 expression is tightly controlled by the activity of multiple signaling receptors, and activation of NF- $\mathrm{kB}$ results in activation of the NLRP3 inflammasome and resultant IL- $1 \beta$ production [46]. In the present study, we showed that increased production of ROS (Fig. 7a) and increased NF-kB activation (Fig. 4k) were seen in the kidney of vehicle + ASLN mice and these effects were significantly inhibited by Citral. This finding is in agreement with our previous report that Citral administration can markedly inhibit NF-kB p65 activation in the kidney cortex in a renal inflammation and fibrosis model in mice [34]. Furthermore, renal NLRP3 levels in vehicle + ASLN mice were increased and renal posttranslational processing of caspase- 1 and IL- $1 \beta$ promoted, all suggestive of NLRP3 inflammasome activation, and these effects were inhibited in Citral + ASLN mice (Fig. 5). However, a decrease of NLRP3 levels and IL-1 $\beta$ and increases in Nrf2 levels in kidneys after Citral treatment compared to vehicle treatment (Figs. 5a and 7g), which may result from the reduced recruitment of macrophages into the kidney after treatment, but this may be part of the mechanisms involved in these proteins in the protective effects of Citral. A selective Nrf2 agonist, bardoxolone, has been found to enhance the magnitude of proteinuria in a rat model of diabetic nephropathy [47], but was found to be beneficial in the prevention and therapy of tissue injury in an animal model of cancer [48, 49]. Further studies are needed to resolve these conflicting results and determine the mechanistic pathways involved.

\section{Conclusion}

Citral alleviates the mouse ASLN model by inhibition of the activation signal of NLRP3 inflammasome and enhanced activation of Nrf2 antioxidant signaling.

\section{Abbreviations}

ANOVA: analysis of variance; ASLN: accelerated and severe lupus nephritis; BUN: blood urea nitrogen; COX-2: cyclooxygenase-2; Cr: creatinine; ELISA: enzyme-linked immunosorbent assay; FITC: fluorescein isothiocyanate; IFN: interferon; IL: interleukin; IP: intraperitoneal; LN: lupus nephritis; LPS: lipopolysaccharide; NF-kB: nuclear factor kappa-light-chain-enhancer of activated B cells; NLRP3: NACHT, LRR and PYD domains-containing protein 3; Nrf2: nuclear factor E2-related factor 2; OD: optical density; PE: phycoerythrin; PGE2: prostaglandin E2; RLU: reactive luminescence units; ROS: reactive oxygen species; SEM: standard error of the mean; SLE: systemic lupus erythematosus; TUNEL: terminal deoxynucleotidyl transferase dUTP nick end labeling.

\section{Competing interests}

The authors declare that they have no competing interests.

\section{Authors' contributions}

All authors were involved in drafting the article critically for important intellectual content, and all authors approved the final version to be published. S-MK performed animal studies, analyzed the data, and drafted the manuscript. J-CL performed experiments using macrophage cell lines and analyzed the data. T-JL performed experiments using peritoneal macrophages and analyzed the data. F-CL performed clinical analysis. LKC and C-LH prepared the Citral. L-TY performed flow cytometry. H-KS analyzed the data of flow cytometry. K-FH and $\mathrm{AC}$ are the guarantors of 
this work and, as such, had full access to all the data in the study and take responsibility for the integrity of the data and the accuracy of the data analysis.

\section{Acknowledgements}

This study was supported by grants NSC102-2628-B-197-001-MY3 and NSC 102-2320-B-016-006-MY3 from the Ministry of Science and Technology, and TSGH-C104-073 from the Tri-Service General Hospital, National Defense Medical Center, Taipei, Taiwan, ROC

\section{Author details}

'Graduate Institute of Aerospace and Undersea Medicine, National Defense Medical Center, Taipei, Taiwan. ${ }^{2}$ Department of Pathology, Tri-Service General Hospital, National Defense Medical Center, No. 325, Sec. 2, Cheng-Gung Road, Taipei, Taiwan, ROC. ${ }^{3}$ Graduate Institute of Life Sciences, National Defense Medical Center, Taipei, Taiwan. ${ }^{4}$ Division of Rheumatology/ Immunology and Allergy, Department of Medicine, Tri-Service General Hospital, National Defense Medical Center, Taipei, Taiwan. ${ }^{5}$ Department of Cosmeceutics, China Medical University, Taichung, Taiwan. ${ }^{6}$ Division of Wood Cellulose, Taiwan Forestry Research Institute, Taipei, Taiwan. ${ }^{7}$ Department and Graduate Institute of Microbiology and Immunology, National Defense Medical Center, Taipei, Taiwan. ${ }^{8}$ Department of Biotechnology and Animal Science, National Ilan University, Sec. 1, Shen-Lung Road, Ilan 260Taiwan, ROC.

\section{Received: 2 July 2015 Accepted: 29 October 2015}

\section{Published online: 19 November 2015}

\section{References}

1. Weening JJ, D'Agati VD, Schwartz MM, Seshan SV, Alpers CE, Appel GB, et al. The classification of glomerulonephritis in systemic lupus erythematosus revisited. J Am Soc Nephrol. 2004;15(2):241-50.

2. Mittal B, Hurwitz S, Rennke H, Singh AK. New subcategories of class IV lupus nephritis: are there clinical, histologic, and outcome differences? Am J Kidney Dis. 2004;44(6):1050-9.

3. Tam LS, Li EK, Lai FM, Chan YK, Szeto CC. Mesangial lupus nephritis in Chinese is associated with a high rate of transformation to higher grade nephritis. Lupus. 2003;12(9):665-71.

4. Haas KM, Watanabe R, Matsushita T, Nakashima H, Ishiura N, Okochi H, et al. Protective and pathogenic roles for $\mathrm{B}$ cells during systemic autoimmunity in NZB/WF1 mice. J Immunol. 2010;184(9):4789-800.

5. Su W, Madaio MP. Recent advances in the pathogenesis of lupus nephritis: autoantibodies and B cells. Semin Nephrol. 2003;23(6):564-8.

6. Tucci M, Stucci S, Strippoli S, Silvestris F. Cytokine overproduction, T-cell activation, and defective T-regulatory functions promote nephritis in systemic lupus erythematosus. J Biomed Biotechnol. 2010;2010:457146.

7. Casciola-Rosen LA, Anhalt G, Rosen A. Autoantigens targeted in systemic lupus erythematosus are clustered in two populations of surface structures on apoptotic keratinocytes. J Exp Med. 1994;179(4):1317-30.

8. Aringer M, Smolen JS. Cytokine expression in lupus kidneys. Lupus. 2005;14(1):13-8

9. Tsai PY, Ka SM, Chang JM, Chen HC, Shui HA, Li CY, et al. Epigallocatechin-3gallate prevents lupus nephritis development in mice via enhancing the Nrf2 antioxidant pathway and inhibiting NLRP3 inflammasome activation. Free Radic Biol Med. 2011;51(3):744-54.

10. Zhao J, Wang H, Dai C, Wang H, Zhang H, Huang Y, et al. P2X7 blockade attenuates murine lupus nephritis by inhibiting activation of the NLRP3/ ASC/caspase 1 pathway. Arthritis Rheum. 2013;65(12):3176-85.

11. Faust J, Menke J, Kriegsmann J, Kelley VR, Mayet WJ, Galle PR, et al. Correlation of renal tubular epithelial cell-derived interleukin-18 up-regulation with disease activity in MRL-Faslpr mice with autoimmune lupus nephritis. Arthritis Rheum. 2002;46(11):3083-95.

12. Lu B, Nakamura T, Inouye K, Li J, Tang Y, Lundback P, et al. Novel role of PKR in inflammasome activation and HMGB1 release. Nature. 2012;488(7413):670-4.

13. Latz $E$, Xiao TS, Stutz A. Activation and regulation of the inflammasomes. Nat Rev Immunol. 2013;13(6):397-411.

14. Hua KF, Yang SM, Kao TY, Chang JM, Chen HL, Tsai YJ, et al. Osthole mitigates progressive IgA nephropathy by inhibiting reactive oxygen species generation and NF-kappaB/NLRP3 pathway. PLoS One. 2013;8(10):e77794.
15. Kahlenberg JM, Kaplan MJ. The inflammasome and lupus: another innate immune mechanism contributing to disease pathogenesis? Curr Opin Rheumatol. 2014;26(5):475-81.

16. Zhao J, Wang H, Huang Y, Zhang H, Wang S, Gaskin F, et al. Lupus nephritis: Glycogen synthase kinase 3beta promotes renal damage through activation of NLRP3 inflammasome in lupus-prone mice. Arthritis Rheumatol. 2015;67(4):1036-44.

17. Jiang T, Tian F, Zheng H, Whitman SA, Lin Y, Zhang Z, et al. Nrf2 suppresses lupus nephritis through inhibition of oxidative injury and the NF-kappaBmediated inflammatory response. Kidney Int. 2014;85(2):333-43.

18. Shah $D$, Wanchu A, Bhatnagar A. Interaction between oxidative stress and chemokines: possible pathogenic role in systemic lupus erythematosus and rheumatoid arthritis. Immunobiology. 2011;216(9):1010-7.

19. Mukhopadhyay P, Rajesh M, Pan H, Patel V, Mukhopadhyay B, Batkai S, et al. Cannabinoid-2 receptor limits inflammation, oxidative/nitrosative stress, and cell death in nephropathy. Free Radic Biol Med. 2010;48(3):457-67.

20. Moroni G, Novembrino C, Quaglini S, De Giuseppe R, Gallelli B, Uva V, et al. Oxidative stress and homocysteine metabolism in patients with lupus nephritis. Lupus. 2010;19(1):65-72.

21. Kim HJ, Vaziri ND. Contribution of impaired Nrf2-Keap1 pathway to oxidative stress and inflammation in chronic renal failure. Am J Physiol Renal Physiol. 2010;298(3):F662-71.

22. Yoh K, Itoh K, Enomoto A, Hirayama A, Yamaquchi N, Kobayashi M, et al. Nrf2-deficient female mice develop lupus-like autoimmune nephritis. Kidney Int. 2001;60(4):1343-53.

23. Ma Q, Battelli L, Hubbs AF. Multiorgan autoimmune inflammation, enhanced lymphoproliferation, and impaired homeostasis of reactive oxygen species in mice lacking the antioxidant-activated transcription factor Nrf2. Am J Pathol. 2006;168(6):1960-74.

24. Jin W, Wang H, Ji Y, Zhu L, Yan W, Qiao L, et al. Genetic ablation of Nrf2 enhances susceptibility to acute lung injury after traumatic brain injury in mice. Exp Biol Med (Maywood). 2009;234(2):181-9.

25. Jin W, Wang H, Yan W, Xu L, Wang X, Zhao X, et al. Disruption of Nrf2 enhances upregulation of nuclear factor-kappaB activity, proinflammatory cytokines, and intercellular adhesion molecule-1 in the brain after traumatic brain injury. Mediators Inflamm. 2008;2008:725174.

26. Liu M, Reddy NM, Higbee EM, Potteti HR, Noel S, Racusen L, et al. The Nrf2 triterpenoid activator, CDDO-imidazolide, protects kidneys from ischemiareperfusion injury in mice. Kidney Int. 2014;85(1):134-41.

27. Tsai PY, Ka SM, Chang JM, Lai JH, Dai MS, Jheng HL, et al. Antroquinonol differentially modulates $\mathrm{T}$ cell activity and reduces interleukin-18 production, but enhances Nrf2 activation, in murine accelerated severe lupus nephritis. Arthritis Rheum. 2012;64(1):232-42.

28. Yang SM, Chan YL, Hua KF, Chang JM, Chen HL, Tsai YJ, et al. Osthole improves an accelerated focal segmental glomerulosclerosis model in the early stage by activating the Nrf2 antioxidant pathway and subsequently inhibiting NF-kappaB-mediated COX-2 expression and apoptosis. Free Radic Biol Med. 2014;73:260-9.

29. Iyer SS, He Q, Janczy JR, Elliott El, Zhong Z, Olivier AK, et al. Mitochondrial cardiolipin is required for Nlrp3 inflammasome activation. Immunity. 2013;39(2):311-23.

30. Wang G, Pierangeli SS, Papalardo E, Ansari GA, Khan MF. Markers of oxidative and nitrosative stress in systemic lupus erythematosus: correlation with disease activity. Arthritis Rheum. 2010;62(7):2064-72.

31. Bachiega TF, Sforcin JM. Lemongrass and citral effect on cytokines production by murine macrophages. J Ethnopharmacol. 2011;137(1):909-13.

32. Cheel J, Theoduloz C, Rodriguez J, Schmeda-Hirschmann G. Free radical scavengers and antioxidants from Lemongrass (Cymbopogon citratus (DC.) Stapf.). J Agric Food Chem. 2005;53(7):2511-7.

33. Barroso MF, Noronha JP, Delerue-Matos C, Oliveira MB. Flavored waters: influence of ingredients on antioxidant capacity and terpenoid profile by HS-SPME/GC-MS. J Agric Food Chem. 2011;59(9):5062-72.

34. Yang SM, Hua KF, Lin YC, Chen A, Chang JM, Kuoping Chao L, et al. Citral is renoprotective for focal segmental glomerulosclerosis by inhibiting oxidative stress and apoptosis and activating Nrf2 pathway in mice. PLoS One. 2013;8(9):e74871.

35. Yang SM, Ka SM, Wu HL, Yeh YC, Kuo CH, Hua KF, et al. Thrombomodulin domain 1 ameliorates diabetic nephropathy in mice via anti-NF-kappaB/ NLRP3 inflammasome-mediated inflammation, enhancement of NRF2 antioxidant activity and inhibition of apoptosis. Diabetologia. 2014;57(2):424-34 
36. Savarese E, Steinberg C, Pawar RD, Reindl W, Akira S, Anders HJ, et al. Requirement of Toll-like receptor 7 for pristane-induced production of autoantibodies and development of murine lupus nephritis. Arthritis Rheum. 2008:58(4):1107-15.

37. Ka SM, Sytwu HK, Chang DM, Hsieh SL, Tsai PY, Chen A. Decoy receptor 3 ameliorates an autoimmune crescentic glomerulonephritis model in mice. J Am Soc Nephrol. 2007;18(9):2473-85.

38. Chao TK, Rifai A, Ka SM, Yang SM, Shui HA, Lin YF, et al. The endogenous immune response modulates the course of IgA-immune complex mediated nephropathy. Kidney Int. 2006;70(2):283-97.

39. Hua KF, Chou JC, Ka SM, Tasi YL, Chen A, Wu SH, et al. Cyclooxygenase-2 regulates NLRP3 inflammasome-derived IL-1 beta production. J Cell Physiol. 2015:230(4):863-74.

40. Nishijima CM, Ganev EG, Mazzardo-Martins L, Martins DF, Rocha LR, Santos AR, et al. Citral: a monoterpene with prophylactic and therapeutic anti-nociceptive effects in experimental models of acute and chronic pain. Eur J Pharmacol. 2014;736:16-25.

41. Dinarello CA. Immunological and inflammatory functions of the interleukin-1 family. Annu Rev Immunol. 2009;27:519-50.

42. Mishra BB, Rathinam VA, Martens GW, Martinot AJ, Kornfeld H, Fitzgerald KA, et al. Nitric oxide controls the immunopathology of tuberculosis by inhibiting NLRP3 inflammasome-dependent processing of IL-1 beta. Nat Immunol. 2013;14(1):52-60.

43. Yang Q, Stevenson HL, Scott MJ, Ismail N. Type I interferon contributes to noncanonical inflammasome activation, mediates immunopathology, and impairs protective immunity during fatal infection with lipopolysaccharidenegative ehrlichiae. Am J Pathol. 2015;185(2):446-61.

44. Yu J, Nagasu H, Murakami T, Hoang H, Broderick L, Hoffman HM, et al. Inflammasome activation leads to Caspase-1-dependent mitochondrial damage and block of mitophagy. Proc Natl Acad Sci U S A. 2014;111(43):15514-9.

45. Liao PC, Chao LK, Chou JC, Dong WC, Lin CN, Lin CY, et al. Lipopolysaccharide/ adenosine triphosphate-mediated signal transduction in the regulation of NLRP3 protein expression and caspase-1-mediated interleukin-1 beta secretion. Inflamm Res. 2013;62(1):89-96.

46. Segovia J, Sabbah A, Mgbemena V, Tsai SY, Chang TH, Berton MT, et al. TLR2/MyD88/NF-kappaB pathway, reactive oxygen species, potassium efflux activates NLRP3/ASC inflammasome during respiratory syncytial virus infection. PLoS One. 2012;7(1):e29695.

47. Zoja C, Corna D, Nava V, Locatelli M, Abbate M, Gaspari F, et al. Analogs of bardoxolone methyl worsen diabetic nephropathy in rats with additional adverse effects. Am J Physiol Renal Physiol. 2013;304(6):F808-19.

48. Liby KT, Yore MM, Sporn MB. Triterpenoids and rexinoids as multifunctional agents for the prevention and treatment of cancer. Nat Rev Cancer. 2007;7(5):357-69.

49. Sporn MB, Liby KT, Yore MM, Fu L, Lopchuk JM, Gribble GW. New synthetic triterpenoids: potent agents for prevention and treatment of tissue injury caused by inflammatory and oxidative stress. J Nat Prod. 2011;74(3):537-45.

\section{Submit your next manuscript to BioMed Central and take full advantage of:}

- Convenient online submission

- Thorough peer review

- No space constraints or color figure charges

- Immediate publication on acceptance

- Inclusion in PubMed, CAS, Scopus and Google Scholar

- Research which is freely available for redistribution

Submit your manuscript at www.biomedcentral.com/submit 